\title{
Effects of Cooling Water Velocity on Temperature Field of Hot Billet Conveyor Roller
}

\author{
PAN Cunhai ${ }^{1, a}$, LUO Sa ${ }^{2, b}$ \\ ${ }^{1}$ College of Mechanical Engineering, Tianjin University of Science and Technology, Tianjin 300222, \\ China \\ ${ }^{2}$ College of Mechanical Engineering, Tianjin University of Science and Technology, Tianjin 300222, \\ China \\ amepanch@163.com, 'luosatj@163.com
}

\begin{abstract}
Keywords: conveyor roller; temperature field; cooling water velocity; Fluent; thermal wear.
Abstract. In the process of rollers transport the hot billets, if the roller's temperature is too high, the roller material will arouse thermal wear due to overheating, and reducing its mechanical properties. This paper analyzes the effects of different cooling water velocities on the cooling effect by Fluent. The results show that the cooling effect can be best, and the lower water consumption when the water velocity is $0.1 \mathrm{~m} / \mathrm{s}$. The study provides basis for evaluating the temperature field of billet conveyor roller and controlling the cooling water flow.
\end{abstract}

\section{Introduction}

The phenomenon of concave on the conveyor roller surface is the result of thermal wear, and it is caused by the hot billets direct contact the conveyor rollers in a long term. So the cooling effect of the cooling water is very significant for the rollers operation and the billets quality. The steelmakers are the main water consumers. Considering the steel industries water conservation demand ${ }^{[1-2]}$, this paper analyzes the effects of different cooling water velocities on the cooling effects by Fluent, and gets the optimum velocity of the cooling water. Thus provides basis for saving water and controlling the cooling water flow. According to the materials provided by factory, conveyor roller possible overheating layer thickness is analyzed, thus lay a foundation to understand the transfer roller's thermal wear mechanism.

\section{Model building}

\section{Definite conditions}

Definite conditions include initial conditions, boundary conditions, geometric and physical conditions [3-5].

In rectangular coordinate system, the field variables of the transient temperature field should meet the following differential equation:

$$
\rho c \frac{\partial T}{\partial t}-\frac{\partial}{\partial x}\left(k_{x} \frac{\partial T}{\partial x}\right)-\frac{\partial}{\partial y}\left(k_{y} \frac{\partial T}{\partial y}\right)-\frac{\partial}{\partial z}\left(k_{z} \frac{\partial T}{\partial z}\right)-\rho Q=0
$$

In the formula: $\rho$ is the material density; $c$ is materials specific heat; $t$ is time; $Q$ is the objects internal heat source density.

The system initial state is given by the initial conditions:

$$
\left.T\right|_{t=0}=f(x, y, z)
$$

The initial temperature field is uniform. When $\mathrm{t}=0, T=T_{a}, T_{a}$ is the ambient temperature.

Boundary condition at inlet is the cooling water velocity, and its temperature is:

$$
T=T_{w}
$$

In the formula: $T_{w}$ is cooling water temperature.

The conveyor roller surface and the air free convection heat transfer:

$$
q=h\left(T_{a}-T\right)
$$


In the formula: $q$ is heat flux intensity transit from air to temperature field; $h$ is convection coefficient; $T$ is temperature.

The radiation heat flux intensity of the hot billet to conveyor roller is analyzed according to Stephen - boltzmann's law. Heat transfer form between the conveyor roller and hot billet interface is heat conduction. Make the following simplified for ease of calculation, to simplify the heat transfer for thermal load, and load on the conveyor roller.

When temperature is $1273 \mathrm{k}, 35 \mathrm{CrMo}$ material physical parameters as shown in table $1 .{ }^{[6]}$ :

Tab.1 Material physical parameters

\begin{tabular}{cccc}
\hline Material & Density $\left[\mathrm{kg} / \mathrm{m}^{3}\right]$ & $\begin{array}{c}\text { Specific heat capacity } \\
{\left[\mathrm{J} / \mathrm{kg} \cdot{ }^{\circ} \mathrm{C}\right]}\end{array}$ & $\begin{array}{c}\text { Thermal conductivity } \\
{\left[\mathrm{W} / \mathrm{m} \cdot{ }^{\circ} \mathrm{C}\right]}\end{array}$ \\
\hline $35 \mathrm{CrMo}$ & 7900 & 0.55 & 28.56 \\
\hline
\end{tabular}

\section{Model building ${ }^{[7]}$}

Since the conveying roller length is $4200 \mathrm{~mm}$, and an outside diameter is $370 \mathrm{~mm}$, a length much greater than its diameter, so the temperature field simulation model can be simplified as a two-dimensional plane problem, further selection conveying roller midsection simulated distribution of temperature field. Gambit is adopted to establish the model and mesh, as shown in figure1 (a), (b). Axial model partitioning grid number is 35520 , the node number is 35909 . Radial model partitioning grid number is 18009 , node number is 18243 .

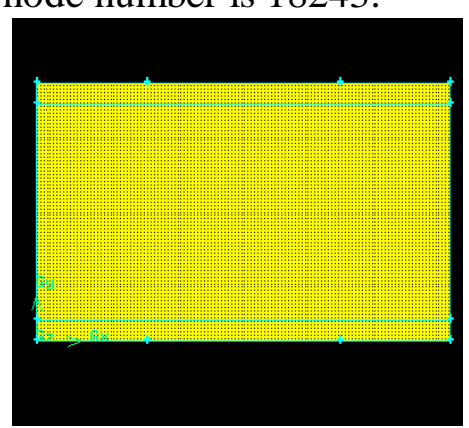

(a) Roller axial meshing

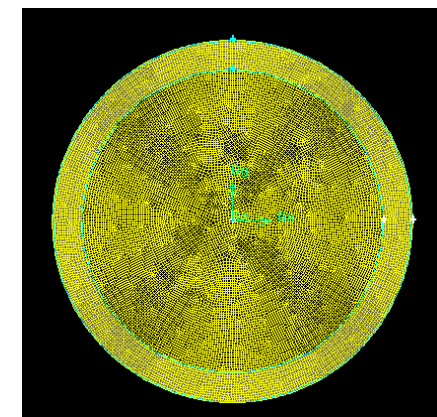

(b) Roller radial meshing

Fig. 12 D model of conveyor roller

The establishment of the model based on the following assumptions: $\square$ Considering the length of conveyor roller is $4200 \mathrm{~mm}$ larger than the width of billet $300 \mathrm{~mm}$, so choosing $600 \mathrm{~mm}$ to build the model;(2) The roller spacing is $1200 \mathrm{~mm}$, ignoring the heat exchange between the hot billet; (3)Only considering the thermal contact in heat transfer process between the billet and conveyor roller, ignoring the thermal radiation of the hot billet to the roller profile; (4) According to the data provided by the manufacture, the hot billet temperature is about $1273 \mathrm{~K}$, the roller material is $35 \mathrm{CrMo}$, and its long-term working temperature is $773 \mathrm{~K}$; (5) Ignoring the friction heat between the billet and the roller.

According to the Reynolds number to judge when the cooling water flow rate is $0.1 \mathrm{~m} / \mathrm{s}$, the water status is turbulent. Choosing the standard $\mathrm{k}$ - epsilon turbulence model to simulate.

\section{The simulation results and analysis}

\section{Without cooling water the conveyor roller temperature distribution}

When the hot billets forward with the rotation of the conveying rollers, each in different parts of the transport roller continuous contact with the hot billets time is about $15 \mathrm{~s}$, conveying roller rotation angle is about 720 degrees. Using Fluent software to simulate the conveyor roller temperature distribution. Due to a fault without cooling water inside the roller, considering this extreme condition, and simulating the temperatures distributions of conveyor roller within the range of $30 \mathrm{~mm}$ thickness.

Simplified simulation condition, the maximum heat load is evenly loaded $1273 \mathrm{~K}$ on the roller outer wall, the results of the temperatures distributions of conveyor roller within the range of $30 \mathrm{~mm}$ thickness are shown in Figure 2. As can be seen from Figure 2, when the transfer roller filled with air 
instead of water cooling, 15 seconds after contact with the hot billets, within $2 \mathrm{~mm}$ of the surface temperature is very high, $28 \mathrm{~mm}$ thickness range within which the temperature is higher than $773 \mathrm{~K}$, and reached high temperatures limits which the material can withstand, thus have serious adverse effects on the mechanical properties of the conveying roller, so it can be concluded that the conveying rollers can not long without cooling water.

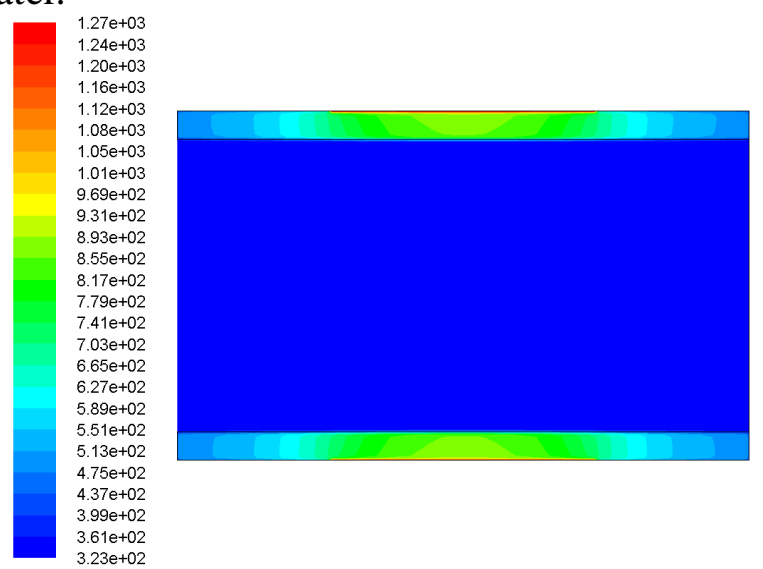

Fig. 2 Temperature field under no cooling water

\section{Determining the flow rate of the cooling water}

The thermal load of $1273 \mathrm{~K}$ is evenly loaded on the outer surface of the conveyor roller. Setting different flow rates to simulate the temperature distributions of $30 \mathrm{~mm}$ thickness from the outer layer to the inner wall. Choose 12 different cooling water flow rate conditions, and then simulate the temperature distribution in thickness $30 \mathrm{~mm}$ range of the conveyor roller. The results are shown in Figure 3.

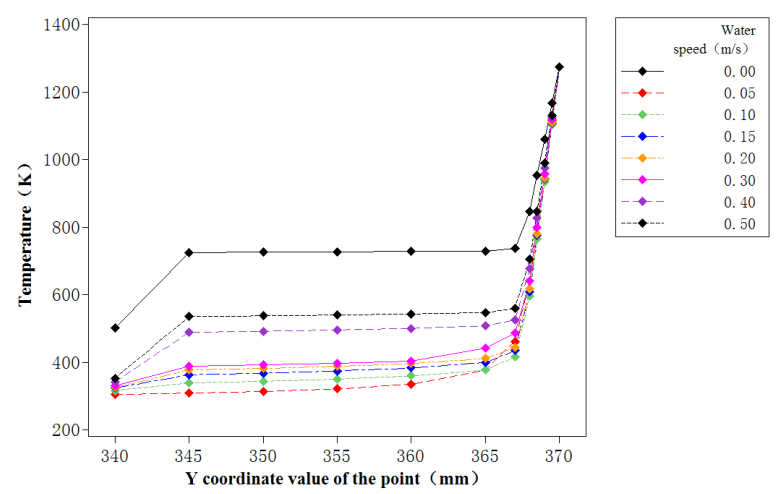

Fig.3 Each layer temperature of rollers under different cooling water velocities

It can be seen from the figure 3, the simulation results are as follows: cooling water from the static to the water flow velocity of $0.5 \mathrm{~m} / \mathrm{s}$ range, about surface depth of $1.5 \mathrm{~mm}$ range of temperature is higher than the temperature of the material can withstand $773 \mathrm{~K}$, the conveyor roller's temperature is too high to cause material thermal wear by overheating; Further analysis of the cooling water flow rate is not the sooner the better, the best cooling water velocity is about $0.1 \mathrm{~m} / \mathrm{s}$.

In this case, it not only has good cooling effect but also has low water consumption. However, the internal relations between water flow rate and cooling effect or rule is not very clear, its reason remains to be further researched.

\section{Conveyor roller temperature distribution under moving thermal load}

The thermal loads moves with the conveyor roller rotates in actual production, if the heat load of $1273 \mathrm{~K}$ is evenly loaded on the outer surface of the roller, the simulation results will differ from the actual. Now the temperature distribution under moving thermal loads is analyzed, and the cooling water flow rate is $0.1 \mathrm{~m} / \mathrm{s}$.

The outer circumference of the conveyor roller can be divided into 15 parts; each corresponds to $24^{\circ}$ circular surface. Set the air temperature $323 \mathrm{~K}$, convection coefficient is $5 \mathrm{~W} /(\mathrm{m} 2 \cdot \mathrm{k})$. Based on the above conditions to simulate the temperature distributions, the result at $15 \mathrm{~s}$ is shown in Figure 4 . From 
the picture we can see the temperatures are uneven distributed. The maximum temperatures of inner wall and outer wall are $343 \mathrm{~K}$ and $1273 \mathrm{~K}$ respectively, and the local transport roller surface temperature is over $773 \mathrm{~K}$.

From the Figure 4, it can be seen that the billet and the conveyor roller generate heat conduction partly, when the thermal load is loaded on roller surface intermittently.Since the rest of the roller is internally cooled by water, the temperature drops quickly. However, an arc surface which contact with the hot billet is still overheating. The overheated layer thickness is about $1.5 \mathrm{~mm}$ ( temperature at $\mathrm{R} 183.5 \mathrm{~mm}$ is $770.43 \mathrm{~K})$.

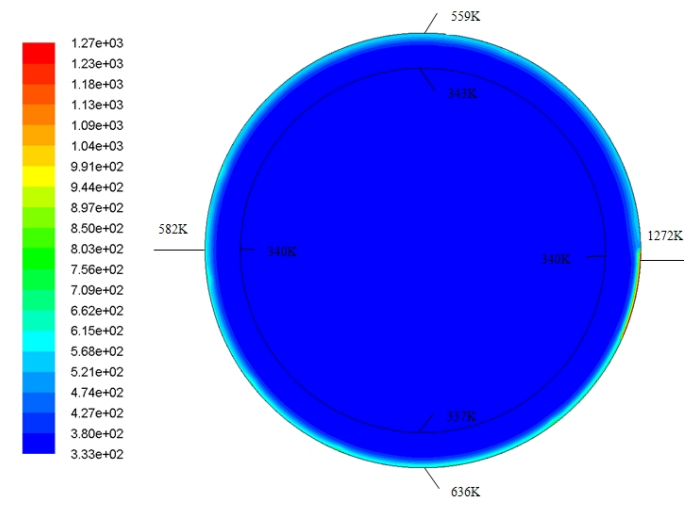

Fig.4 Temperature distribution at 15th second of conveyor roller under the moving thermal load

\section{Conclusions}

(1)With the constant and uniform heat load, after 15s thermal contact, the temperature of the conveyor roller is high in the $2 \mathrm{~mm}$ of the surface, and the temperature gradient is great. The cooling water does has an important impact on the life of the conveyor rollers, and conveyor rollers can not without cooling water for a long time.

(2) When the flow rate is $0.1 \mathrm{~m} / \mathrm{s}$, the cooling effects can be best and the water consumption is low, thus provides basis for evaluating the temperature field of billet conveyor roller and controlling the cooling water flow.

(3)When the thermal load is loaded on roller surface intermittently, the hot billet and the conveyor roller generate heat conduction partly. Since the rest of the roller is internally cooled by water, the temperature drops quickly. However, an arc surface which contact with the hot billet is still overheating. The overheated layer thickness is about $1.5 \mathrm{~mm}$. Temperatures of other parts of the roller have dropped to the scope of the material can withstand. The overheating layer thickness provides reference data for interpreting the phenomenon of thermal wear of the conveyor roller.

\section{References}

[1] Xinchuang Li, Jijun Cheng: Metallurgical Economics and Management (2007), 04, p. 4-6 .

[2] Zhichao Chen, Zhigang Wang, Yourong Li: Metallurgical Equipment (2010), 181, p. 12 -15 .

[3] Peng Zhang: Research on the temperature field model of hot roller intermediate slab and transfer roller and its application. Wuhan:Wuhan University of Science and Technology (2008).

[4] Jianxin Hong, Pu Hong, Bin Li: Hot Working Technology Vol.44 (2015), p. 156-158.

[5] Hongwu Zhang, Yuanxian Gu, Wanxie Zhong: Chinese Journal of Solid Mechanics Vol.21 (2000), p. 217-223.

[6] Meiling Yuan, Lijuan Zhang, Yi Liu: Electrical Technology (2012), 05, p. 57-60. 
[7] Yong Yu, in: Fluent introductory and advanced tutorials. Beijing: Beijing Institute of Technology Press (2008). 